\title{
Sustentabilidade Ambiental e Responsabilidade Social na cadeia de moda Brasileira: uma proposta de aproveitamento de sobras de tecido
}

\author{
Environmental Sustainability and Social Responsibility in the Brazilian \\ fashion chain: a proposal for reuse of fabric leftovers
}

\section{HELD, Maria Silvia Barros de}

Universidade de São Paulo - USP I silviaheld.usp@gmail.com

SANCHES, Regina

Universidade de São Paulo - USP I regina.sanches@usp.br

COUTINHO, Caroline Oliveira Pimentel

Universidade de São Paulo - USP I caroline.pimentel@solvay.com

FERREIRA, Daniela Ester

Universidade de São Paulo - USP I danief@uol.com.br

TOSHIO, JONAS II WADA

Universidade de São Paulo - USP I toshito.wada@gmail.com

HUBNER, Paula

Universidade de São Paulo - USP I pahubner@hotmail.com

ARAÚJO, Yasmin

Universidade de_São Paulo - USP I vasminnarauio@hotmail.com

\begin{abstract}
Resumo
O presente artigo visa apresentar uma proposta para incorporar a sustentabilidade e responsabilidade social em uma empresa de produção de vestuário. Expõe a importância do tema em estudo, referências literárias sobre sustentabilidade e a cadeia de moda no Brasil. Propõe ainda um modelo coeso e eficaz para o aproveitamento de sobras dentro de uma indústria de confecção, usando a metodologia de projeto de produto de Bomfim (1975).

Palavras-chave:

sustentabilidade,
\end{abstract} responsabilidade social, confecção, sobras. 


\section{INTRODUC̣ÃO}

Atualmente as consequências do modelo econômico global têm ocupado significativos espaços nos debates promovidos pelos meios de comunicação. A cada dia, são levantados debates nos mais variados meios. Alguns exemplos: preocupantes mudanças climáticas devido ao aquecimento global; as catástrofes provocadas; a degradação da biodiversidade; o consumo desenfreado; a excessiva geração de resíduos sólidos e descarte inadequado; a possibilidade de esgotamento de recursos hídricos em algumas regiões e a preocupação com a falta de ética com as condições no ambiente de trabalho. Esses assuntos também têm sido um dos principais motivos de apreensão por parte de algumas empresas e organizações. Na verdade, além de ser resultantes de algumas obrigatoriedades estabelecidas pelos governos, são consequências que provocam danos que impactam no modo de vida e no cotidiano das pessoas. E as empresas que desejam manter sua longevidade em termos de mercado e lucratividade, devem estar atentas aos seus consumidores, cada vez mais conscientizados em relação às questões ambientais.

É importante enfatizar que as novas tecnologias permitiram o acesso a informações que antes eram restritas à elite, e as redes sociais facilitaram o compartilhamento dessas informações os empoderando enquanto cidadãos e consumidores. Daí porque essa nova condição permitiu que os indivíduos se transformassem em protagonistas, que opinam, fiscalizam, protestam e que vêm demostrando estarem mais atentos a posicionamentos e ações das empresas. Nota-se também que, além da preocupação com problemas ligados à sustentabilidade ambiental, algumas inquietações se voltam para questões humanitárias que envolvem os direitos trabalhistas, a segurança e a dignidade nos locais de trabalho.

Em termos ambientais, o momento atual pode ser considerado présustentável. A transição ainda está em processo e se consolidará assim como ocorreu com as normas e leis trabalhistas, que não existiam em épocas passadas e hoje integram a rotina das empresas. Essa pré-sustentabilidade é um divisor de águas entre a economia predatória e a economia social e ambientalmente responsável. O modelo contemporâneo de desenvolvimento guia os negócios a buscar inovação e não há inovação sem sustentabilidade. Esses dois conceitos se tornaram inseparáveis uma vez que a essência da inovação está diretamente relacionada com os objetivos e desafios da sustentabilidade: conciliar as dimensões econômica, social e ambiental. Para Smeraldi (2015) a meta é a ideia de crescimento empresarial ancorado como um todo na sustentabilidade.

A pressão sobre temas ligados à sustentabilidade é maior em indústrias detentoras de visibilidade e significativo impacto ambiental, o que abrange a indústria da moda. Isso se deve à sensibilização e a tomada de consciência a respeito de práticas de consumo mais equilibradas por causa do uso de enormes volumes de recursos naturais e do acúmulo de lixo. Por esse motivo a atenção tem se voltado para o impacto das práticas da cadeia têxtil sobre o 
meio ambiente. Sabe-se que a cadeia têxtil ocupa a quarta posição entre as indústrias mais poluentes (EPA, 2013). Outro fator impactante na percepção de valor dos consumidores sobre as atividades da cadeia têxtil tem sido a questão ética que envolve a mão de obra empregada em todo setor, mas, em particular, na indústria de confecção. Depois das frequentes denúncias nas redes sociais contra a exploração de trabalho e a notícia do acidente em um prédio de confecções em Bangladesh em 2013, um número cada vez maior de consumidores tem passado a se preocupar com suas escolhas de consumo.

Esse contexto e a informação de que a indústria de confecção é a maior empregadora de todas as atividades da cadeia de moda brasileira e o elo que mais apresenta desafios, serviram de base para elaboração desse artigo. Seu objetivo é apresentar uma proposta para incorporar os princípios de sustentabilidade ambiental e responsabilidade social nas práticas de empresas de produção de vestuário que ainda não tenham esses valores associados aos seus produtos e a sua imagem de marca.

Os modelos de negócio baseados em valores são, atualmente, o que há de mais inovador no marketing contemporâneo ao promover a importância da significação. Os consumidores não estão procurando somente produtos e serviços que satisfaçam suas necessidades latentes, aspiram também às experiências proporcionadas por organizações que contemplem o lado espiritual. O marketing 3.0 traz um enfoque mais sofisticado no consumidor, na medida em que considera as abordagens mais colaborativas, culturais e espirituais de cada indivíduo (KOTLER, 2010). Esses aspectos nortearam a presente proposta de aproveitamento de sobras de confecção. Para justificar a relevância desse estudo e embasar essa sugestão, o artigo foi dividido em três partes. A primeira parte, a introdução, expõe a importância do tema e os objetivos da pesquisa; a segunda parte consiste em uma revisão da literatura sobre sustentabilidade e a cadeia de moda no Brasil; em seguida então, propõe um modelo de aproveitamento de sobras dentro de uma indústria de confecção, usando a metodologia de projeto de produto de Bomfim (1975); a terceira parte apresenta as conclusões do estudo.

\section{SUSTENTABILIDADE AMBIENTAL}

\subsection{Um breve histórico do conceito de desenvolvimento sustentável}

A sustentabilidade ambiental vem sendo foco de inúmeros debates na contemporaneidade. Desde meados dos anos 60 do século $X X$, cientistas, ambientalistas e líderes globais têm se preocupado com questões relacionadas com problemas que põem em risco o futuro do planeta: a utilização dos recursos naturais, a preservação de ecossistemas, as inter-relações do desenvolvimento econômico da humanidade com o meio ambiente e a manutenção desses recursos para as futuras gerações, incluindo ainda os aspectos da justiça social e ética. 
O tema foi introduzido na agenda dos debates globais durante a Conferência das Nações Unidas para o Meio Ambiente Humano realizada em Estocolmo na Suécia, em 1972 (SACHS, 2001). Entretanto, somente anos mais tarde, em 1987, por ocasião da criação da Comissão Mundial sobre o Meio Ambiente pela ONU que das discussões acerca das questões ambientais se formalizou o conceito de Desenvolvimento Sustentável. Intitulado Nosso Futuro Comum ou como ficou popularmente conhecido, Relatório Brundtland, foi um marco nos debates que envolviam desenvolvimento econômico e meio ambiente. Nele foi definido o conceito de desenvolvimento sustentável como sendo aquele que atende às necessidades do presente, sem comprometer a capacidade das futuras gerações de suprir as suas próprias necessidades (CMMAD, 1991). Mas foi a partir da Eco-92, a Conferência das Nações Unidas sobre o Meio Ambiente e o Desenvolvimento, realizada em junho de 1992 no Brasil, que o conceito se popularizou. Desde então, passou a chamar a atenção da opinião pública e das instituições privadas para a urgência de se olhar para as questões ambientais e para os desafios sociais e econômicos de um modelo de desenvolvimento que afeta o modo de vida contemporâneo.

O reconhecimento do conceito de sustentabilidade se desenvolveu em três fases. A primeira delas se caracterizou pelo momento em que as pessoas tomaram conhecimento a respeito da finitude dos recursos naturais e pela percepção da necessidade de uma mudança de comportamento em relação à natureza e ao convívio social. No entanto, nesse primeiro momento essa responsabilidade foi delegada ao Estado, às organizações não governamentais e aos ativistas. Já na segunda fase, a pressão social foi a precursora da vontade política e reforçada pela mídia; a questão ambiental evoluiu para um movimento político e organização de partidos cujos discursos e ideologias se fundamentam nessa premissa. A terceira fase foi definida pela resposta do mercado às novas demandas da sociedade, pela adequação de empresas e organizações a um novo cenário e o surgimento de uma série de estudos e certificações dos institutos de tecnologia e da academia (ZULAUF, 2000).

\subsection{Desenvolvimento Sustentável nas Empresas}

A intenção primordial do desenvolvimento sustentável é promover a harmonia entre os seres humanos e a natureza (BERLIM, 2012). Para tanto, é preciso que se repense o paradigma do desenvolvimento econômico atual. Embora teça graves críticas ao modelo econômico capitalista e ao consumo e descarte desenfreado, o desenvolvimento econômico não se opõe ao crescimento. Não só porque se baseia em promover o desenvolvimento material sem colocar em risco a capacidade dos recursos naturais, como também em promover a inclusão social, tendo como estratégia de implementação uma abordagem integrada de longo prazo, envolvendo a sociedade civil, as instituições e governos.

A perspectiva da sustentabilidade é fazer a transição de uma sociedade 
em que o bem-estar e a economia não sejam mais medidos pelo crescimento da produção e pelo consumo de matéria-prima, para uma sociedade em que seja possível viver melhor, se consumindo menos e reduzindo a produção de bens materiais sem o desequilíbrio da economia. Condição que poderá ocorrer no prazo de algumas décadas, mas que irá requerer a ativação de um processo transparente e compartilhado dos objetivos a serem atingidos (MANZINI; VEZZOLI, 2008).

O Eco desenvolvimento deve percorrer um caminho de oito aspectos essenciais: a satisfação das necessidades básicas; a solidariedade com as gerações futuras; a participação da população envolvida; a preservação dos recursos naturais e a proteção do meio ambiente; a elaboração de um sistema social que garanta emprego; a segurança social; o respeito a outras culturas e programas de educação. Esses aspectos se aplicam principalmente às regiões subdesenvolvidas (SACHS, 2001). A agenda da sustentabilidade se apoia em um tripé composto de pilares de igual valor: justiça social, viabilidade econômica e preservação ambiental (ELKINGTON, 2001). Percebe-se que esse conceito não abarca somente o impacto das atividades econômicas no meio ambiente; mas, sobretudo, impacta nas consequências dessas relações nas condições humanas, na qualidade de vida e no bem-estar da sociedade. $O$ desenvolvimento sustentável vai muito além do modelo atual de crescimento econômico, que não só coloca em risco a integridade do meio ambiente e a continuidade da vida na Terra, como também promove a exclusão da igualdade e da dignidade humanas (MANZINI; VEZZOLI, 2008).

As inovações da economia que se deseja são principalmente de caráter social e criadas e realizadas pelos grupos de pessoas diretamente envolvidas no problema a ser solucionado, e não apenas por especialistas e políticos. $\mathrm{Na}$ complexa sociedade contemporânea já se constatam passos significativos na direção da sustentabilidade. Trata-se do resultado de múltiplas iniciativas tomadas por uma variedade de pessoas, associações, empresas e governos locais. Todos, de diferentes pontos de partida, chegaram aos valores comunitários e ao senso de bem comum. Esses passos guiarão a sociedade para a adesão a um sistema de produção fundamentado em redes colaborativas de pessoas e novas relações entre o local e o global.

O novo século, marcado por desafios socioambientais de grande inflexão, demanda da indústria a ressignificação do design, indo além da função de oferecer facilidade à vida dos consumidores. Ressignificação que envolve tanto soluções restauradoras, que tem como propósito proteger e preservar os sistemas vivos do planeta (incluindo a espécie humana), como também promover o engajamento dos consumidores com essas propostas. Segundo Manzini (2010), somente as experiências colaborativas podem levar a uma redução significativa do consumo, e aí reside o futuro do design.

A transição para a sustentabilidade tem na articulação entre o Life Cycle Design e o design para a sustentabilidade os fundamentos para o aparecimento 
de uma nova geração de produtos e serviços intrinsecamente mais sustentáveis. O primeiro considera as implicações ambientais ligadas às fases do ciclo de vida do produto (pré-produção, produção, distribuição, uso e descarte), para minimizar os possíveis efeitos negativos; já o design para a sustentabilidade remete a uma forma de design estratégico na medida em que requer gerir de modo coordenado: produtos, serviços e comunicações para responder à procura social de bem-estar e utilizando uma quantidade de recursos ambientais consideravelmente inferior comparado aos níveis já praticados.

O design cada vez mais é compreendido como a capacidade humana de planejar e produzir desenlaces desejáveis. Ao levar em consideração o avanço da humanidade, a turbulência da contemporaneidade, tem-se um novo design que alcança a condição de vida dos consumidores, não se restringindo apenas aos aspectos ambientais. O termo design sustentável surgiu do advento do movimento da sustentabilidade e projeta qualquer tipo de solução sob a perspectiva do futuro, como princípio norteador da criatividade no presente.

\subsection{Sustentabilidade, Responsabilidade Social e a Indústria de Moda Brasileira}

O Brasil é um dos maiores produtores de têxteis do mundo; ocupa a quarta posição entre os maiores produtores de artigos de vestuário e a quinta posição entre os produtores de manufaturas têxteis (ABIT, 2015). É o único país que possui uma cadeia têxtil completa, que abrange desde as indústrias de fiação, tecelagens, malharias, beneficiamento têxtil, confecção até o setor de varejo. "No ocidente, a indústria brasileira possui o maior parque produtivo integrado, da fibra ao produto final" (UNIETHOS, 2013, p.21).

Embora o Brasil seja um grande produtor e consumidor de têxteis e de vestuário, sua participação no comércio global é insignificante; ocupando a 23a posição no ranking de exportadores, o que significa menos de 0,5\% do total mundial. A sustentabilidade é considerada a principal alternativa para fazer frente à economia globalizada, aos novos valores impostos por ela e restabelecer a competividade na cadeia (UNIETHOS, 2013).

A indústria de confecção atua entre a indústria têxtil e o varejo e segundo dados do IEMI (2011) é a maior empregadora de todas as atividades da cadeia de moda; cerca de 1.645 .087 pessoas atuam em 32.629 empresas (número que considera somente empresas com cinco ou mais trabalhadores registrados). Esse setor é considerado o elo mais frágil da cadeia têxtil por ser bastante pulverizado, intensivo em mão de obra e com a predominância de micro e pequenas empresas. Isso porque a grande maioria dessas empresas adota uma política de preços baixos como estratégia de concorrência, o que em geral, implica em uma necessidade de redução de custos e a terceirização da produção. Essa condição além de contribuir para que o relacionamento entre empresas seja desorganizado e de curto prazo, facilitando as subcontratações, aumenta o risco de descumprimento de condições mínimas de segurança e da legislação 
trabalhista (UNIETHOS, 2013). No entanto, há também um número expressivo de empresas de médio porte que são bem estruturadas e que, em grande parte, são as fornecedoras das marcas e das empresas mais representativas do varejo têxtil. É no contexto desse segmento que se situa a presente proposta de um modelo para introdução de práticas que contemplem a sustentabilidade ambiental no processo produtivo de confecção. Partiu-se do pressuposto de que empresas de porte médio tenham mais visibilidade e que dessa forma, sejam mais suscetíveis às exigências do mercado e aos novos comportamentos de consumo. Por meio de brainstormings para a geração de alternativas, definiuse direcionar as sobras de tecido para o desenvolvimento de um produto idealizado com o intuito de reduzir ao máximo o descarte de resíduos têxteis.

\section{METODOLOGIA}

Bomfim (1995) considera metodologia de projeto como sendo o estudo dos métodos e ferramentas aplicados às ações de definição, organização e solução de problemas teóricos e práticos. Para o autor, o método é o processo usado para se chegar a uma solução e envolve a avaliação de todas as características e etapas pelas quais um produto ou serviço deverá passar para atender às funções estabelecidas. De acordo com as inúmeras possibilidades de modelos de negócios que caracterizam a indústria de confecção brasileira e o contexto no qual se encontra, propõe-se que a implantação de um projeto de reaproveitamento de sobras contemple um planejamento detalhado, mediante uma metodologia descritiva. Considerando-se todas as circunstâncias e desafios expostos anteriormente que envolvem essa indústria, concluiu-se que, para desenvolver tal proposta, a hibridização dos métodos 2 e 4 propostos por Bonfim (1995) seria a opção mais adequada. O método 4 de Bonfim (1975), consiste em um modelo de ramificações das operações e se ajusta perfeitamente a proposta do projeto, pois, possibilita mais agilidade e fluidez do trabalho por apresentar etapas independentes que podem ser realizadas simultaneamente. Porém, como alguns feedbacks serão imprescindíveis no desenrolar do projeto, combinaremos com o método 2 do mesmo autor, que apresenta como característica principal a possiblidade de reavaliação das operações em algumas etapas do processo de produção.

\section{PROJETO PARA APROVEITAMENTO DE SOBRAS DE TECIDOS DE CONFECC̣ÃO}

\subsection{Compreensão das necessidades}

Presumindo que as empresas dentro do escopo da proposta não possuam nenhum direcionamento ligado à sustentabilidade (nem em produtos com insumos sustentáveis, tampouco em práticas e processos internos), o primeiro obstáculo avaliado foi a dificuldade de se introduzir tais valores e ações sem causar uma percepção negativa do público da marca, parecendo uma mera 
ação promocional ou oportunismo. Dessa forma, este estudo sugere que nesses casos, o planejamento de projetos para introdução de práticas que atendam aos propósitos do desenvolvimento sustentável presuma a implantação por etapas.

A partir da revisão bibliográfica sobre o tema, considerou-se o conceito de tripé como fundamentação para a sustentabilidade ambiental: a diminuição dos resíduos sólidos no que concerne aos impactos no meio ambiente, a educação ambiental junto aos consumidores, stakeholders e comunidade, e a responsabilidade social. Considerando os aspectos sociais e o caráter integrador, o projeto prevê além da redução do desperdício pelo aproveitamento de sobras de tecido, a criação de parcerias com empresas locais para o fornecimento dos insumos necessários para confecção da aplicação e um trabalho de capacitação e formação junto à população do entorno da confecção, dando preferência a pessoas com pouca qualificação e que estejam fora do mercado de trabalho. A aplicação desses recursos resultará em um produto com alto valor agregado a ser trabalhado com o público da confecção, que será oferecido como brinde a clientes especiais, integrando o portfólio de estratégias de comunicação da empresa.

Em função da necessidade de aprendizado dos processos de corte e costura e da diversidade de tipos e tamanhos de tecidos e malhas que em geral sobram nas confecções, aferiu-se que a aplicação mais adequada seria a fabricação de um nécessaire em patchwork. Devido a uma grande variação na dimensão dos retalhos, optou-se pelo desenvolvimento de dois tamanhos diferentes de nécessaires e um chaveiro (confeccionado com os retalhos não aproveitados para os nécessaires); o que permite que se chegue muito próximo à utilização total do material descartado.

\subsection{Descrição dos processos de soluções}

\subsubsection{Avaliação dos processos: Desperdício}

O desperdício no corte é toda parte do material que não entra na contribuição final da peça (LIDÓRIO, 2008). O desperdício pode aparecer em várias etapas do corte: no planejamento; em uma ficha técnica ou ordem de corte incorreta do PCP; no risco; no encaixe (como há vários métodos de encaixe, a escolha do método errado pode acarretar mais perda); no enfesto (devido à falta de conhecimento ou habilidade do enfestador) e o desperdício proveniente da própria qualidade do material, como por exemplo: furos, manchas, deformidades na orela e fios grossos (ARAúJO, 1996). Essas perdas podem não ficar evidentes durante o processo de corte, mas, aparecer como peças rejeitadas na produção, ou como artigos de $2^{a}$ qualidade, e consequentemente, em número de pedidos devolvidos.

Nesse sentido, a proposta apresentada neste artigo é o aproveitamento dos retalhos da confecção para o desenvolvimento de dois modelos de nécessaires (de dimensões diferentes em decorrência dos tamanhos dos retalhos que em geral sobram das confecções) como solução para o descarte de resíduos, 
diminuindo o desperdício.

\subsection{Compreensão do processo definido: Descrição dos subprocessos existentes e possíveis}

O mininécessaire foi idealizado para ser usado como porta escova e pasta de dentes; e o nécessaire de tamanho médio para o uso de porta maquiagens, ambos com tamanho apropriado para serem acondicionados dentro de uma bolsa feminina.

As sobras do corte serão separadas por tipos e tamanhos de tecidos e, posteriormente, direcionadas para suas respectivas aplicações. As sobras maiores de tecidos planos em poliéster serão destinadas à forração do nécessaire de tamanho médio, sendo cortadas tradicionalmente pelo cortador. As sobras menores serão direcionadas para prensas de corte em dois tamanhos diferentes (8x8 e 5x5) e em seguida, costuradas para formar o patchwork para aplicação na parte externa do nécessaire.

\subsection{Descrição dos sistemas de produtos}

A máquina de prensa fará os cortes nos tecidos no tamanho padrão definido, na forma quadrada de $5 \times 5 \mathrm{~cm}$ para a aplicação de um mininécessaire e $8 \times 8 \mathrm{~cm}$ para um nécessaire médio. Os demais retalhos, caso não se encaixem no tamanho adequado da prensa serão direcionados para a criação de chaveiros. As sobras cortadas nos tamanhos de $5 \times 5 \mathrm{~cm}$ e $8 \times 8$ serão separadas em lotes diferentes e direcionadas para as respectivas células de criação, cada qual com suas especificidades. Os retalhos de tamanho pequeno, que não podem ser aproveitados na máquina de prensa e corte, serão direcionados para o último eixo da célula de produção, onde serão picotados em forma de franjas, unidos na parte superior com anel metálico de aço e encaixados nos zíperes dos nécessaires desenvolvidos pelos dois primeiros eixos da célula de criação.

\subsubsection{Preparação para a costura}

Seção de preparação onde são feitas as primeiras operações de costura nas partes componentes quando ainda separadas. É o setor responsável pelos chuleados, bainhas e demais preparos necessários (ANDRADE FILHO; SANTOS, 1980). A fluidez do trabalho nessa etapa é imprescindível para a produtividade, para a qualidade do produto, para a correta reutilização do material descartado e o aproveitamento dos retalhos finais na fabricação de chaveiros para fixação nos ziperes dos necessaires. É necessário que os aviamentos estejam completos e organizados em caixas para serem encaminhados para a costura (BIERMANN, 2007).

Sugere-se que o espaço físico para abrigar o projeto possua $300 \mathrm{~m}^{2} \mathrm{e}$ um composto de energia trifásico + neutro, 220 V / 50 kVA, 130 ", Cabo Bitola 
HELD, Maria Silvia Barros de, SANCHES, Regina, COUTINHO, Caroline Oliveira Pimentel, ...

$35 \mathrm{~mm}$ e 2 vias necessários para atender a demanda do projeto. Que também possua banheiros masculinos e femininos, extintores de incêndio tipo $A B C$ com sinalização conforme norma de segurança e luminárias de baixo consumo.

\subsubsection{Layout da Produção:}

Figura 1: Gráfico do Layout da Produção

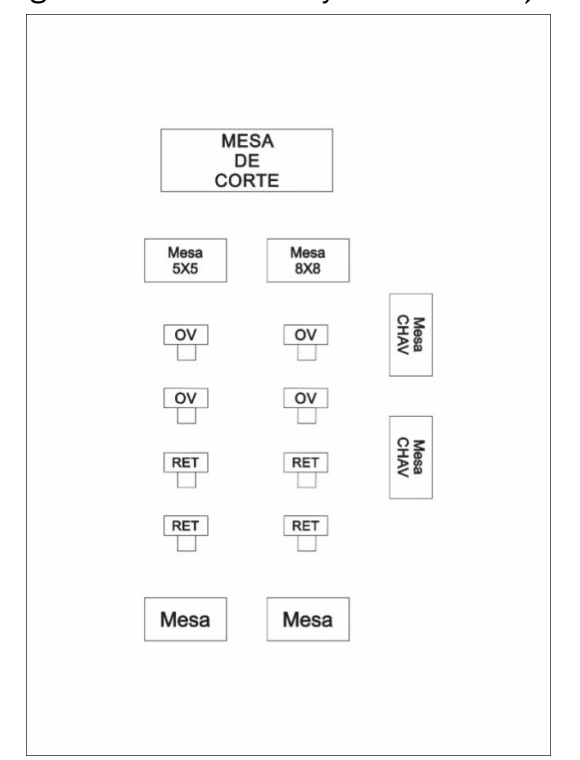

Fonte: Os autores (2015)

\section{Descrição:}

Etapa 1: Mesa de Corte para separação de material (quadrados $5 \times 5$ e $8 \times 8$ ) e tecidos menores para os chaveiros.

Etapa 2: Duas linhas de produção fisicamente iguais que trabalham simultaneamente: mesa de separação dos quadrados já cortados, duas máquinas overloques, duas máquinas retas e uma mesa de acabamento e revisão. Terceira linha de Produção: duas mesas de montagem para os chaveiros.

Figura 2: Fluxograma

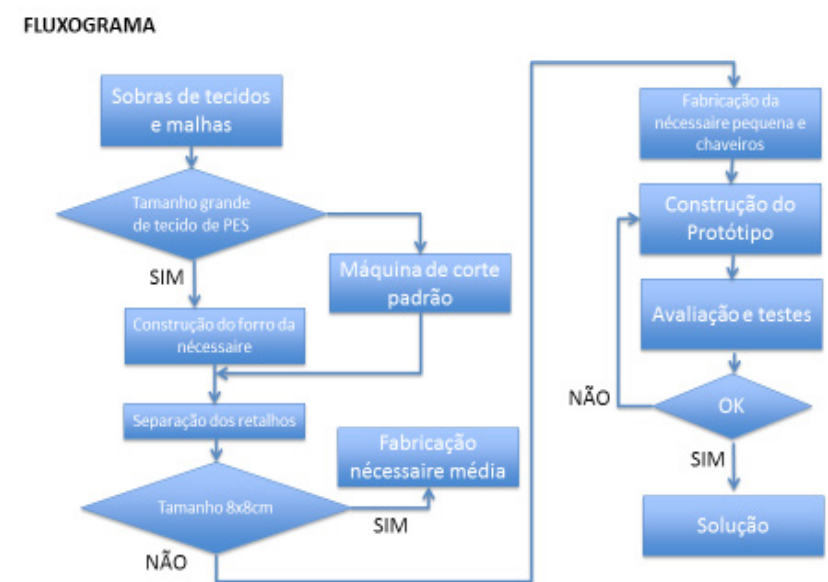

Fonte: Os autores (2015) 


\subsection{Avaliação dos sistemas de produtos}

A organização da produção mais adequada à montagem de determinado produto é um aspecto fundamental; dela depende o rendimento do processo. Num sistema de costura, deve-se considerar os materiais, as máquinas de costura, os operadores, os sistemas de transporte, os métodos de produção e as técnicas de planejamento e controle de produção (ARAÚJO, 1996). O método de Bomfim (1975) foi considerado adequado para a reutilização das sobras do processo produtivo da cadeia principal, sendo contemplada quase a totalidade do descarte das matérias-primas utilizadas nos produtos principais desenvolvidos e fabricados pela empresa.

\section{ANÁLISE: LEVANTAMENTO DOS PRODUTOS DO SISTEMA ELEITO}

Insumos necessários para a fabricação dos nécessaires: as sobras das malhas e tecidos da confecção; zíperes para fechamento dos nécessaires; anéis metálicos de aço para fechamento dos retalhos picotados em franjas; máquinas adequadas para corte padrão dos tecidos e acabamentos necessários e a mão de obra para fabricação dos nécessaires e chaveiros.

\section{DESENVOLVIMENTO: GERAC̣ÃO DE ALTERNATIVAS DE PRODUTOS}

\subsection{Representação das alternativas de projeto}

Figura 3: modelo de referência para Nécessaire Pequeno

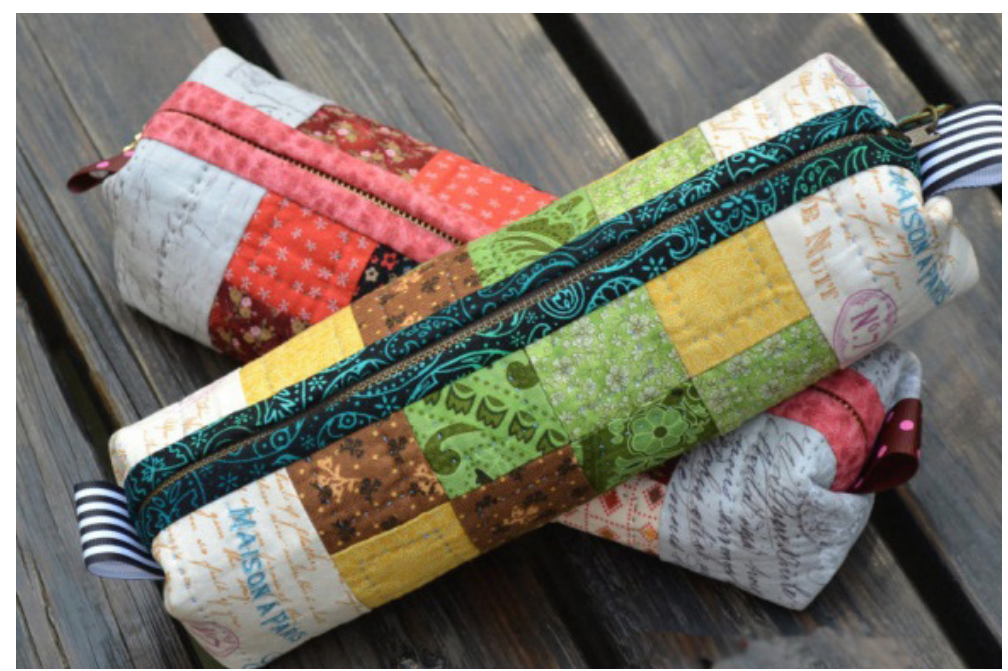

Fonte: DIY Tutorial Ideias² 
Figura 4: modelo de referência para Nécessaire Médio e Chaveiro

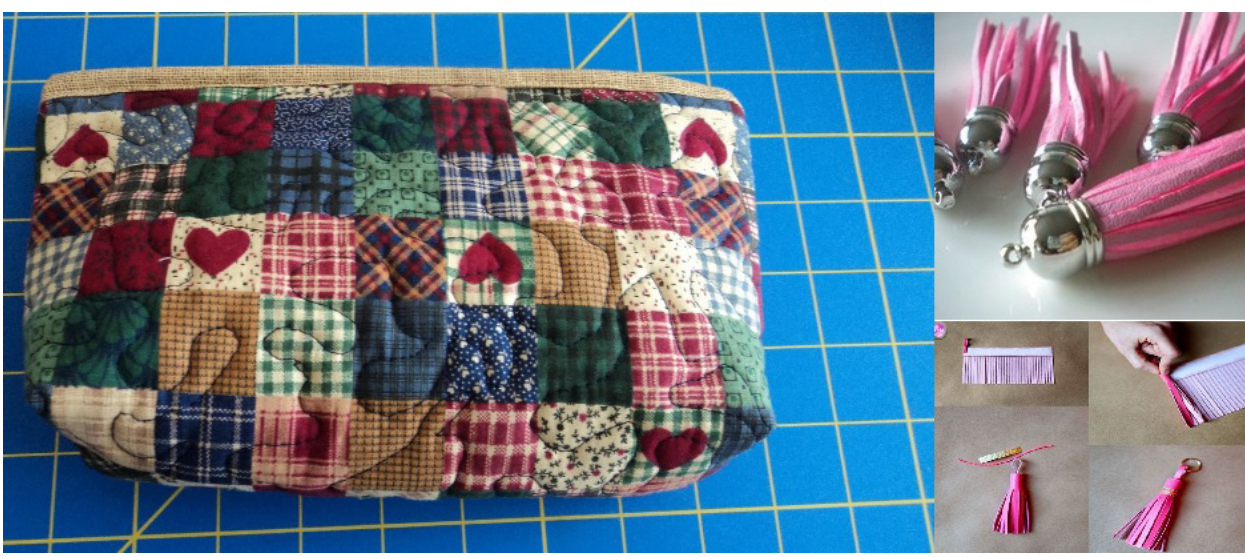

Fonte: Eu e Meus Paninhos Blogspot/A Little Mercerie ${ }^{3}$

\subsection{Avaliação das alternativas de produto}

A geração das alternativas de produto foi considerada nas primeiras etapas do processo de solução dos problemas. Para tanto, empregou-se o método de brainstorms com integrantes do grupo, sendo considerados nessa fase também o custo-benefício que cada opção impactaria na gestão da empresa e o engajamento das equipes participantes do projeto.

\section{IMPLANTAC̣ÃO: MEIOS DE REPRESENTAC̣ÃO PARA O PROCESSO DE FABRICAC̣ÃO E TESTE DE VERIFICAC̣ÃO DOS PROTÓTIPOS}

Após as condições de implementação do projeto ser atendidas, e feita a seleção das pessoas que trabalharão nas Células de Criação, se iniciará o treinamento (estimado em 60h), para posteriormente, desenvolver os protótipos do produto.

\subsection{Lançamento e comportamento do produto no mercado:}

Sugere-se que a partir da fabricação de 100 primeiros nécessaires aprovados pelo departamento de qualidade, seja organizado um evento de lançamento para promover a iniciativa, a organização, os parceiros e as pessoas participantes. O evento poderá contar com a participação dos integrantes do projeto, com os fornecedores parceiros, com os demais colaboradores e acionistas da empresa, além de pessoas influentes e atuantes na comunidade e os familiares das participantes. Poderão ser sorteadas peças de roupa da marca e nécessaires durante o evento.

3 Disponível em: < http://euemeuspaninhos.blogspot.com.br/2010/11/necessairecom-tecido-patchwork.html >; < https://www.alittlemercerie.com/breloque-pompon-simili-cuir. shtml> Acesso em set.2016. 


\section{IMPLANTAC̣ÃO: COMUNICAC̣ÃO}

A empresa irá conciliar as três dimensões da comunicação da sustentabilidade, que se baseiam na informação, na mudança e no processo (CONSELHO EMPRESARIAL BRASILEIRO PARA O DESENVOLVIMENTO SUSTENTÁVEL - CEBDS, 2014). Essas dimensões acontecem quando as empresas fazem a comunicação DA sustentabilidade, a comunicação PARA a sustentabilidade e simultaneamente a sustentabilidade da comunicação, realizada por meio do processo que busca o equilíbrio dos pilares econômico, social e ambiental. A comunicação da sustentabilidade se refere ao o que a empresa faz, como e por que faz, para criar empatia com os públicos de relacionamento. A comunicação para a sustentabilidade tem como objetivo dialogar, mobilizar e educar os diversos públicos de relacionamento. Já a sustentabilidade da comunicação incorpora o processo nas práticas de comunicação corporativa.

A comunicação corporativa é uma das principais ferramentas para o alinhamento entre a imagem e a identidade de uma empresa, ao enunciar além do que produz o que é em que acredita e assim construir sua reputação. Um dos pilares da comunicação integrada, a comunicação corporativa realiza a articulação da comunicação interna e externa, ao estabelecer uma imagem favorável com as partes interessadas. Para isso congrega atividades como propaganda corporativa, relações com a imprensa, comunicação interna e relações com investidores, governos e grupos de interesse. Por meio da mensagem sólida, a empresa faz com que a missão, os valores, a visão e a estratégia de atuação sejam compreendidas, respeitadas e admiradas pelo público de interesse.

O diálogo, o engajamento e a participação serão as ferramentas educativas para a sustentabilidade trabalhadas inicialmente pela empresa, além da ação de relações públicas implementada com a realização do evento para o lançamento do produto. O diálogo por meio da construção de significados é fundamental para conquistar novos modelos operacionais baseados na gestão do conhecimento. A avaliação das capacidades pessoais, a compreensão do processo e as expectativas de resultado são premissas para o estabelecimento do diálogo e suas relações de troca. Esta ótica delineia o sistema, que age na formação comportamental e humana, cujo resultado produz um ambiente propício para o modelo sustentável. Já o engajamento concilia identidades mútuas, é a interação que envolve ativamente o sujeito a despeito das diferenças. A participação abrange a inclusão da diversidade, na medida em que seu significado interfere no acolhimento do outro e suas diferenças, oferecendo condições para que se estabeleça o diálogo e o engajamento.

A viabilidade da estratégia para a sustentabilidade irá demandar a implantação imediata de ações como tornar a intranet disponível para todos os níveis hierárquicos; utilizar comunicação com linguagem clara para todos; 
valorizar relacionamentos dos colaboradores com suas comunidades; estimular o relacionamento com o mundo acadêmico e sobretudo, a empresa manterá o foco na comunicação dos resultados do que foi feito, ao considerar que a toda ação deve vir antes da propagação e os processos em andamento deverão previamente atingir a conclusão.

\section{CONCLUSÃO}

Atualmente percebe-se a intensa necessidade de uma melhor compreensão e conhecimento das práticas sustentáveis dentro das indústrias, em especial, a de confecção de artigos têxteis. Isso porque, nos dias atuais, é a maior empregadora de todas as atividades da cadeia de moda brasileira. Porém, é um dos eixos que mais apresenta desafios a serem superados no que diz respeito à proteção ambiental.

A proposta de incorporação da sustentabilidade e da responsabilidade social em uma empresa de produção de vestuário que não possui esses valores associados à sua imagem de marca apresentada neste artigo, mostrou que, além de ser um projeto com eixos de respeito ambiental, pode ser extremamente rentável e interessante para a organização. As primeiras considerações e pontos a serem avaliados foram sobre as matérias-primas utilizadas no segmento em questão e os valores associados à cadeia. $\mathrm{O}$ maior desafio continua sendo introduzir esses conceitos em empresas que não fazem uso de insumos sustentáveis e não desenvolvem seus produtos e nem ações com esses princípios, sem parecer uma ação oportunista de marketing social ou uma ação guiada somente para promover a imagem da marca junto ao seu público.

Mostrou-se ao longo deste artigo, que, nos dias de hoje, os modelos de negócios baseados em valores como a sustentabilidade ambiental, são vistos como inovadores pelo marketing contemporâneo e promovem um forte impacto positivo nos clientes. Os consumidores não estão procurando somente produtos e serviços que atendam às suas necessidades latentes, mas também aspiram por produtos e experiências que evoquem o seu lado emocional. Esses aspectos nortearam a proposta aqui apresentada, uma vez que se trata do aproveitamento de sobras de confecção e engajamento social.

A metodologia de projeto de produto de Bomfim (1975), foi utilizada neste artigo e permitiu o desenvolvimento de um modelo coeso e eficaz, trabalhando, assim, as variáveis necessárias para a estruturação adequada e correta do projeto, considerando todos os riscos e aspectos vulneráveis envolvidos. Constatou-se então que, mediante uma boa metodologia, forte organização e estrutura adequada, uma corporação do setor de vestuário pode se beneficiar grandemente com práticas sustentáveis e socialmente responsáveis, considerando os aspectos financeiros, mercadológicos, corporativos e a imagem da empresa junto ao seu público. 


\section{REFERÊNCIAS}

ALITTLE MERCERIE. Breloque pompon simili cuir. Disponível em: $<$ https://www.alittlemercerie.com/breloque-pompon-simili-cuir. shtml>. Acesso em: 5 set. 2016.

ANDRADE FILHO, José Ferreira; SANTOS, Laércio Frazão. Introdução à tecnologia têxtil. Rio de Janeiro: SENAI, 1980. v. 3.

ARAÚJO, Mário. Tecnologia do vestuário. Lisboa: Fundação Calouste Gulbenkian, 1996.

ASSOCIAÇÃO BRASILEIRA DA INDÚSTRIA TÊXTIL - ABIT. Agenda de prioridades têxtil e confecção, 2015/2018. Disponível em: <http://www. abit.org.br/Publicacao.aspx\#22>. Acesso em: 10 nov. 2015.

BERLIM, Lilyan. Moda e sustentabilidade: uma reflexão necessária. São Paulo: Estação das Letras e das Cores, 2012.

BIERMANN, Maria Julieta Espindola. Gestão do processo produtivo. Porto Alegre: SEBRAE/RS, 2007.

BOMFIM, Gustavo A. Metodologia para desenvolvimento de projeto. João Pessoa: Universitária/UFPB, 1995

COMISSÃO MUNDIAL SOBRE MEIO AMBIENTE E DESENVOLVIMENTO - CMMAD. Nosso futuro comum. Rio de Janeiro: Editora da Fundação Getúlio Vargas, 1991.

CONSELHO EMPRESARIAL BRASILEIRO PARA O DESENVOLVIMENTO SUSTENTÁVEL - CEBDS. Guia de comunicação e sustentabilidade. 2008. Disponível em: <http://cebds.org/wp-content/ uploads/2014/02/Guia-de-Comunica\%C3\%A7\%C3\%A3o-eSustentabilidade.pdf>. Acesso em: 17 nov. 2015.

DIY TUTORIAL IDEAS. Pouch. Disponível em: <http://www. handmadiya.com/ search/label/Pouch>. Acesso em: 9 set. 2016.

ELKINGTON, John. Canibais com garfo e faca. São Paulo: Makron Books, 2001.

ENVIROMENTAL PROTECTION AGENCY - EPA. Environmental Topics. 2013. Disponível em: <http//www.3.epa.gov>. Acesso em: 10 nov. 2015.

EU E MEUS PANINHOS. Necessaire com tecido. Disponível em: <http:// euemeuspaninhos.blogspot.com.br/2010/11/necessaire-com-tecidopatchwork.html>. Acesso em: 5 set. 2016. 
INSTITUTO DE ESTUDOS E MARKETING INDUSTRIAL - IEMI.

Relatório Setorial da Indústria Têxtil Brasileira. 2011. Disponível em: < http://www.iemi.com.br/biblioteca/publicacoes-setoriais/>. Acesso em: 10 jul. 2017.

KOTLER, Philip. Marketing 3.0. Rio de Janeiro: Elsevier. 2010.

LIDÓRIO, Cristiane Ferreira. Tecnologia da confecção. Araranguá: Instituto Federal de Educação, Ciência e Tecnologia de Santa Catarina, 2008. Apostila. Disponível em: <http://wiki.ifsc.edu.br> Acesso em: 10 nov. 2015.

MANZINI, Ezio. Prefácio. In: MORAES, Dijon. Metaprojeto: o design do design. São Paulo: Edgard Blücher. 2010.

MANZINI, Ezio; VEZZOLI Carlo. O desenvolvimento de produtos sustentáveis. São Paulo: Edusp, 2008.

SACHS, Ignacy. Caminhos para o desenvolvimento sustentável. Rio de Janeiro: Garamond, 2001.

SMERALDI, Roberto. Não há inovação sem sustentabilidade no mundo dos negócios. Disponível em: <http://sustentabilidade.sebrae.com.br/ sites/Sustentabilidade>. Acesso em: 10 nov. 2015.

UNIETHOS. Sustentabilidade e competitividade na cadeia de moda: estudos setoriais. São Paulo: Uniethos, 2013.

ZULAUF, Werner. O meio ambiente e o futuro. Estudos Avançados, São Paulo, v. 14, n. 39, maio/ago. 2000. Disponível em: <http://dx.doi. org/10.1590/S0103-40142000000200009>. Acesso em 09 nov.2015. 